\title{
Existe uma literatura negra em Portugal?
}

\section{Does a Black Literature in Portugal Exist?}

Bianca Mafra Gonçalves ${ }^{1}$

\begin{abstract}
RESUMO
Uma nova perspectiva surge na literatura portuguesa: a perspectiva negra. Contribuindo para a desconstrução do imaginário consagrado acerca da identidade lusitana e, também, fomentando a revisitação do legado colonial do país, as três obras aqui analisadas colocam em cena o processo de "tornar-se negro/a" em Portugal. Em vista disso, seria possível analisar esta produção a partir do conceito de "literatura negra"?
\end{abstract}

PALAVRAS-CHAVE: Literatura negra; Portugal.

\section{ABSTRACT}

A new perspective emerges in Portuguese literature: the black perspective. Contributing for the deconstruction of the established imagery about the Portuguese identity, and also fomenting the revisitation of the colonial legacy of the country, the three pieces analyzed here introduce the process of "becoming black" in Portugal. Thereby, would it be possible to analyze this production through the concept of "black literature"?

KEY WORDS: Black Literature; Portugal

\footnotetext{
${ }^{1}$ Mestranda em Estudos Comparados de Literaturas de Língua Portuguesa, com pesquisa intitulada Em torno da filosofia de um cabelo crespo: uma análise de Esse Cabelo, de Djaimilia Pereira de Almeida.
} 


\section{Negros e portugueses}

José Ramos Tinhorão, em seu Negros em Portugal: uma presença silenciosa (1988), destaca a importância da participação negro-africana na vida social, econômica e cultural portuguesa. Neste estudo pioneiro, Tinhorão cartografa o extenso arquivo negro português, verificando o papel dos negros escravizados no projeto expansionista lusitano, a integração dos negros no mercado de trabalho, a presença destes em irmandades e confrarias religiosas; passando pelo plano artístico-cultural, com a representação dos negros na literatura de cordel, nos textos teatrais pré-vicentinos e vicentinos, incluindo a importante pesquisa de Tinhorão sobre a origem negra do fado-canção em Lisboa.

Embora seja relativamente abundante o material que confirma a presença significativa de negros e negras na cultura portuguesa, pouco se produziu a respeito do tema ao longo do século $X X$, justamente, século em que foram flagradas inúmeras lutas por autonomia e resistência ao discurso hegemônico ocidental. Para Stuart Hall, o século XX foi responsável por alguns "des-centramentos" da identidade moderna, dentre eles o impacto dos "novos movimentos sociais", confirmadas pela atuação das "revoluções estudantis, dos movimentos anti-guerra e da contra-cultura jovem, das lutas pelos direitos civis, dos movimentos revolucionários do 'Terceiro Mundo', dos movimentos pacifistas, e de todo o resto associado a '1968'" (HALL, 1998, p. 34). Contudo, apesar de as principais nações terem se voltado a tais insurgências, em especial às de caráter racial, Portugal não apenas se manteve em silêncio, como também tentou silenciar as possibilidades de descentramentos.

No que diz respeito ao caso específico de Portugal, podemos atribuir parte deste silenciamento ao salazarismo. Regime que atravessou quatro décadas, o Estado Novo português, em seus primeiros movimentos, reproduziu os argumentos do racismo científico que movia a Alemanha nazista, graças a 
etnólogos esforçados em "constatar" que o povo lusitano estava livre dos "vestígios das influências negríticas ou simplesmente negróides" (TINHORÃO, 1988, p. 405). A derrota dos alemães ao final da Segunda Guerra Mundial, além de culminar na condenação dos projetos de purismo racial, também trouxe novos modelos e dispositivos diplomáticos no cenário internacional, como a Declaração dos Direitos do Homem (1948), que estabeleceu a autodeterminação como direito fundamental, e a Organização das Nações Unidas, que "passou a atribuir às potências coloniais a obrigação de prepararem os territórios sob sua administração para a independência" (CASTELO, 2010, p. 14). Portugal, que até então mantinha seus domínios coloniais (não só em África como também em Ásia), começa a ser confrontada pelo novo establishment, sendo obrigado a investir em novos discursos.

É neste contexto que o autor de Casa Grande \& Senzala passa a desempenhar um papel fundamental à intelligentsia salazarista. A convite de Sarmento Rodrigues, Gilberto Freyre dá início a seu roteiro de visitas pelas chamadas "terras lusitanas", atravessando África e Índia portuguesas, entre agosto de 1951 e fevereiro de 1952. Sob a perspectiva que marcou seu livro publicado em 1933, Freyre elabora em várias conferências e ensaios aquilo que se tornará a ideologia oficial do salazarismo: o lusotropicalismo. Para Freyre, o português

confraternizou com os povos de cor em vez de procurar dominá-los do alto de torres como que profiláticas onde raça e cultura imperialmente europeias se mantivessem misticamente puras. (...) para assegurar a permanência, o vigor, a unidade dessa civilização fundada pelo português - a lusotropical - precisamos, em face de certos problemas, de agir, e não apenas pensar e de sentir, lusotropicalmente. (FREYRE, 2010, p. 131-132)

A fim de justificar a permanência lusitana em África, Freyre lançou mão de estratégias retóricas que concebiam o português como "criador" de um novo tipo de relação entre colonizador e colonizado que, segundo ele, descendia da própria constituição étnica do português: 
O português, por ter sabido sempre ligar a estes valores os da Europa, ao sangue das mulheres de cor seu sangue de brancos desde a Europa misturados a mouros, judeus, berberes, criou culturas lusotropicais que, no Brasil como na África e no Oriente, distinguem-se nitidamente das passivamente subeuropeias, criadas pelos europeus imperiais como simples obras d'arte política. Engenharia social, nos trópicos, raramente a souberam praticar estes europeus: continua a ser uma especialização portuguesa. (FREYRE, 2010, p. 141)

Este suposto hibridismo racial do português, continua Freyre, foi o responsável pela "redução à quase insignificância do preconceito de raça, e ao mesmo tempo com a valorização, maior ou menor, do mestiço sob aqueles vários aspectos" (FREYRE, 2010b, p. 28). Recombinando, dessa forma, os elementos que marcaram o discurso de harmonia racial em Casa Grande \& Senzala dentro do espaço colonial africano, Freyre teve suas ideias absorvidas pelas novas formulações salazaristas.

A propaganda encarregou-se disso, de forma incansável: era urgente moldar o pensamento para conformar a ação. Nas vésperas do fim do império, quando os movimentos de libertação nacional combatiam o colonialismo português em Angola, Guiné e Moçambique, o processo de apropriação discursiva do lusotropicalismo pelo Estado Novo foi "radicalizado": paradoxalmente, o Estado colonial português esforça-se por inculcar a norma antirracista nos portugueses e adaptar o comportamento dos funcionários administrativos e dos colonos ao ideário lusotropicalista. (CASTELO 2010, p. 17)

Tal investimento retórico, obviamente, não impediu o desenvolvimento de uma consciência pró-libertação, seja nas lutas ou nas letras. Graças não apenas à leitura do repertório afro-americano e da Negritude francófona, a convivência de africanos na Casa dos Estudantes do Império (CEI) fomentou a "assimilação de uma cultura propícia ao espírito crítico" e, por consequência, "aos primeiros tentames de uma cultura própria, em sintonia com as suas terras" (LARANJEIRA, 1994, p. 102). 
O neologismo "negritude" - ou melhor, négritude - é fundado poeticamente em Cahier d'un Retour au Pays Natal (Diário de um Retorno ao País Natal), extenso poema composto pelo martinicano Aimé Césaire em 1939, que enuncia uma voz lírica negra que procura se reconciliar com suas origens, projetando uma viagem de regresso à África. No florescer da Negritude lusófona, Francisco José Tenreiro e Mário Pinto de Andrade organizam o caderno de Poesia negra de expressão portuguesa; Noémia de Sousa publica, na revista Mensagem, os poemas "Sangue Negro" e "A negra"; além das reflexões teóricas de autores negros de língua portuguesa, como o de Bessa Victor (LARANJEIRA, 1994, p. 111-114).

Do outro lado, a tarefa da intelectualidade salazarista, convertida aos ideais lusotropicalistas, consistia em sufocar quaisquer manifestações que contrariassem o imaginário de fraternidade do colonizador português. Este tipo de esforço pôde ser flagrado no ensaio de Maria da Graça Freire, publicado pela Agência-Geral do Ultramar, intitulado Portugueses e Negritude (1971). Após saudar o "universalismo dos portugueses", Freire deslegitima a tendência negritudinista dos poetas das colônias africanas de língua portuguesa:

Acontece que na África Portuguesa alguns falsos poetas negros esboçaram há anos, em vão, uma corrente de Negritude plagiada no movimento afro-francês. Sob a máscara artificial da Negritude a poesia era propaganda política, escreve Bessa Victor. Seguiam talvez na esteira de Mário de Andrade, o qual publicara juntamente com Tenreiro o Primeiro Caderno de Poesia Negra de Expressão Portuguesa e considerava prejudicial para as Artes Negras o contacto de uma certa Europa com a África. Sem darem por isso, aqueles 'falsos poetas', querendo estremar-se da sua família portuguesa, manifestavam um defeito (às vezes qualidade) do português, que facilmente se embriaga na administração dos outros menosprezando-se a si próprio, ao seu passado, à sua cultura. A Arte não compraz com mistificações e vinga-se devolvendo-lhes um pastiche em vez de obra de Arte. O que realmente havia a esperar, a revelação do sentir poeta português com sangue negro, não está lá; é um artifício, uma coisa convencional. (FREIRE, 1971, p. 37-38) 
Após os processos de independência, de "movimento de contestação literária e artística" a Negritude francófona tornou-se "ideologia de Estado" e, acompanhado da rotinização de alguns de seus expedientes estéticos (DEPESTRE, 1980, s/n), fez com que a enunciação marcadamente negra desaparecesse aos poucos das produções ou, ainda, que fosse assimilada pela retórica freyreana. Um exemplo deste uso conciliador, glosando elementos até então inversamente opostos, está no discurso do primeiro presidente africano a visitar Portugal: Léopold Sédar Senghor. Proferido em 29 de janeiro de 1975 na Academia de Ciências de Lisboa, este "ensaio sobre a cultura negra e suas relações com Brasil e Portugal" procura estabelecer aproximações e afinidades entre as culturas africana e portuguesa. A expansão marítima empreendida de um lado e a exploração escravista sofrida pelo outro - descrita por Senghor como "aventura" (SENGHOR, s.d., p. 22) - são postas em equivalência pelo estadista que, ao longo do discurso, recorrerá à comparação lexical entre a língua portuguesa e línguas africanas, a fim de reafirmar tal irmandade:

Insisti sobre os vários sentidos da palavra "saudade" [a partir de registros de Camões, Camilo Castelo Branco e no uso popular] por ela ser - e lembro novamente a delicadeza - a palavra mais característica da língua, do temperamento, da personalidade portuguesa básica.

E por aqui chegamos ao cerne da ideia de Negritude. Não direi que nas línguas negro-africanas uma palavra possa designar, como sucede com a saudade, as sete significações que inventariei. Este desdobramento, porém, existe também nas línguas do grupo senegalês-guineense. Assim, em wolof a palavra 'nama' tem significados paralelos aos da 'saudade' (...) (SENGHOR, s.d., p. 39-40)

A suposta "delicadeza" do português está, para Senghor, na "sua recusa à violência, no respeito pela vida humana" (SENGHOR, s.d., p. 25), que teria caracterizado, por extensão, o projeto lusitano ultramarino. Não surpreende que o presidente senegalês - também poeta e um dois mais conhecidos escritores da 
Négritude - defenda, ao final de seu discurso, a mestiçagem como solução para tensões raciais, políticas e econômicas, cujo sucesso se encontraria no Brasil:

Numa obra magistral, intitulada Casa Grande \& Senzala (...), o grande sociólogo brasileiro Gilberto Freyre explica-nos como se realizou, nos séculos XVII e XVIII, este milagre de civilização moderna. Todos os depoimentos são unânimes, e em primeiro lugar os dos brasileiros que, no Brasil e publicamente mo confirmariam, foi pela mestiçagem, não só da carne mas também do espírito, que o Português do sonho sebastianista se transformou no brasileiro de hoje: um dos dois Grandes do Novo Mundo, que ao longo do caminho percorrido enriqueceram com as contribuições biológicas e culturais de outras etnias. Esta mestiçagem explica que às características próprias dos pioneiros portugueses, largamente preservadas, se tenham juntado novas aquisições, provenientes todas da África Negra. E, diga-se de passagem, se a gentileza e a doçura do português ali foram preservadas, e até reforçadas, foi a essa presença africana que tal se ficou devendo. (SENGHOR, s.d, p. 48-49)

\section{Negros portugueses}

A questão negra só voltaria à pauta portuguesa nos anos 1980, com a entrada de imigrantes de origem africana, principalmente daqueles nascidos em antigas colônias portuguesas. Angola, Cabo Verde e Guiné-Bissau são os principais países de origem dos novos imigrantes, que atenderam, majoritariamente, às necessidades de setores do mercado de trabalho português carentes de mão-de-obra não-especializada (PADILLA \& ORTIZ, 2012). Porém, o contingente de africanos em Portugal provocou mudanças nas resoluções políticas de estrangeiros. Em 1981, o governo português cria a Lei n. 37/81, na qual se estabelece a nacionalidade jus sanguinis, ou seja, filhos de pai e/ou mãe portugueses são, por direito, portugueses, enquanto que filhos de imigrantes nascidos em Portugal, anteriormente contemplados pela nacionalidade jus soli, devem ter a nacionalidade dos pais (BUALA, 2017). 
No caso dos afrodescendentes, tais restrições foram somadas a outras contradições, como aos paradoxais meios de se aferir a quantidade de negros/as que vivem em Portugal. Diante da inexistência de censos que operem tal tarefa, utiliza-se problematicamente a lei de imigração, que se transforma, por sua vez, em um aparato que contribui para que negros/as nascidos/as em Portugal sintam-se estrangeiros em sua própria terra (HENRIQUES, 2012).

Trabalhos recentes, especialmente no âmbito jornalístico, tem disputado a identidade portuguesa e posto em xeque a homogeneidade subentendida em torno de tal nacionalidade. Colunas assinadas por importantes artistas e ativistas negros, como Mamadou Ba e Kalaf Epalanga, ambos no "Público", bem como a investigação da repórter e aliada da luta antirracista Joana Gorjão Henriques, em seu Racismo em português: o lado esquecido do colonialismo (2017), colocam finalmente em cena, no debate público, o legado pós-colonial de Portugal dentro do território português.

Porém, diferentemente de nações que tradicionalmente se debruçaram sob a questão racial, Portugal tem empreendido esta tarefa em pleno século XXI, num contexto crítico de crise das identidades, no qual se flagra um distanciamento dos cenários coletivos, que tanto marcaram as políticas raciais dos Estados Unidos ou, até mesmo, do Brasil durante a metade do século XX.

No caso da identidade negra em Portugal, outros marcadores, como a chamada "origem" - terminologia passível de problematização - são elementos postos no "jogo das identidades". Expressão cunhada por Stuart Hall para situar as "consequências políticas da fragmentação ou 'pluralização' de identidades" no cenário da alta-modernidade (HALL, 1998, p. 16), ela também nos ajuda a entender a predisposição interseccional da formação das culturas e literaturas negras portuguesas. As obras aqui citadas veiculam esta construção, como veremos a seguir. 


\section{Autoria negra em Portugal}

Sem seguir uma ordem cronológica das obras que inscrevem a (possível) problemática da literatura negra portuguesa, mas acompanhando um continuum de emergência temática, os livros aqui reunidos carregam algumas semelhanças: além de serem escritos por autores negros que vivenciam a identidade portuguesa (em maior ou menor grau), tratam-se de obras em prosa, que podem ser inseridas no guarda-chuva do gênero Romance. No entanto, enquanto Esse Cabelo e Também os brancos sabem dançar compartilham, de formas distintas, a noção de "escritas de si", fazendo fundir, dessa forma, o autor à obra, Um preto muito português apresenta uma narrativa que, embora esteja em primeira pessoa, não se restringe à identidade da autora. ${ }^{2}$

As obras aqui escolhidas também retiram da invisibilidade a experiência racializada no contexto lusitano e, por extensão, combatem o imaginário lusotropicalista, que historicamente pressupôs que o convívio com a diferença multirracial correspondia à "harmonia racial" ou "ausência de preconceitos" (MATA, 2006, p. 290). Ao tratar do racismo, direta ou indiretamente, em primeira pessoa, nossos autores também se inscrevem na temática da autodescoberta do sujeito, muito cara ao repertório das literaturas negras em geral. Trata-se do gesto de "tornar-se negro" que, para a psicanalista brasileira Neusa Santos Souza,

A descoberta de ser negra é mais que a constatação do óbvio. (Aliás, óbvio é aquela categoria que só aparece enquanto tal, depois do trabalho de se descortinar muitos véus). Saber-se negra é viver a experiência de ter sido massacrada em sua identidade, confundida em suas perspectivas, submetidas a exigências, compelida a expectativas alienadas. Mas é também, e sobretudo, a experiência de comprometer-se a resgatar sua história e recriar-se em suas potencialidades. (SOUZA, 1990, p. 17-18)

2 Sobre a escolha de um narrador masculino, a autora confessa em entrevista ao jornal "Público": "Achei que, se fosse uma mulher, muita gente ia achar que estou a falar da minha história" (HENRIQUES, 2018). 


\section{Um preto muito português}

Tvon, que também assina Telma Tvon, é rapper portuguesa nascida em Angola e autora de Um preto muito português. Obra que apresenta a narrativa de Budjurra - português e filho de cabo-verdianos -, sua história também faz um retrato da classe trabalhadora jovem e negra em Portugal. Em meio a preocupações pessoais e sociais, ele se atenta em responder, afinal, quem de fato é Budjurra. Primeiro, passa por questionamentos ligados à identidade, como a questão social, racial e nacional. Neste processo, Budjurra, com a ajuda do irmão, conhece o rap, que se torna um aliado ao despertar por uma consciência negra portuguesa:

O Chullage é um MC português. Um preto Português. Assim como eu e os meus irmãos, é filho de crioulos e nasceu em Portugal. Fala da realidade dos bairros, da realidade dos imigrantes africanos, sobreviventes na terra de Camões. O crioulo dele é melhor que o nosso, muito melhor. O meu irmão bem que se esforça mas não me parece que tenha sucesso na conquista da sua crioulidade. (TVON, 2017, p. 22)

É também em meio a episódios do cotidiano que Budjurra lançará suas reflexões em torno do racismo português. Em um dos capítulos, o funcionário de call-center - destino comum aos imigrantes e filhos de imigrantes africanos denuncia a cobertura midiática de um suposto arrastão na praia, em que os pretos teriam sido taxados como os maiores responsáveis pelo incidente - o que, por sua vez, contribui para a marginalização desta população:

Chegados a casa, fomos apresentados à notícia do dia: Arrastão em Carcavelos. Ficamos mais do que à toa. Segundo os media, cerca de 500 jovens (pretos a julgar pelas imagens) invadiram a praia de Carcavelos com o intuito de assaltar outros banhistas. (...)

A tv indiciava claramente que nós e todos os jovens pretos que tinham ido à praia naquele dia se tinham envolvido em confrontos 
previamente planificados. Silêncio magoado. E tudo isto no dia de Portugal, no dia também da minha amada Lisboa. (...)

Durante muitos dias ainda falei sobre isso com alguns amigos. A minha cabeça parecia um laboratório, procurava amostras de que realmente o que eles estavam a dizer não era tão errado. Se calhar havia mesmo pessoal a gamar e nós não vimos mas não era os 500, porra. Nem havia 500 pretos na praia. E os brancos? (...) Mas na minha cabeça ecoava: então e os media não tinham de investigar? Lançaram assim o alarme sem saber o que se passava? Ouviram apenas uma parte? A mim só me mandaram circular. Ninguém me entrevistou. Mas também iam-me entrevistar porquê? Eu sou preto e é tão natural como a minha sede que o terceiro poder em Portugal está apostado em marginalizar-nos ainda mais (TVON, 2017, p. 27-28)

Contudo, Budjurra não se restringe ao tema do racismo. Nos relatos de sua trajetória pessoal, a personagem também encara reflexões de gênero, graças a seu convívio constante com as mulheres. Outra preocupação do narrador é sua vida afetiva, marcada por uma solidão pungente que, em suas reflexões, acaba cruzando a questão racial. No capítulo intitulado "Desmistificar o black power", Budjurra, ao terminar de ler um ensaio, escrito por uma amiga, sobre a relação do cabelo crespo com a identidade negra, conclui: "eu preciso de me amar mais para vos amar" (TVON, 2017, p. 55)

\section{Também os brancos sabem dançar}

Kalaf Epalanga, autor de Também os brancos sabem dançar, é músico, membro do extinto grupo Buraka Som Sistema, e cronista nas mídias angolanas e portuguesas. Nascido em Angola, em constante trânsito entre Lisboa e Berlim, Epalanga demarca, no cenário lusófono, aquilo que em língua inglesa ficou conhecido por Afropolitan, termo cunhado pela escritora Taiye Selasi a fim de designar a experiência multicultural, transnacional e cosmopolita de africanos que vivem num contexto identitariamente difuso (SELASI, 2005).

Tal complexidade dá forma ao Também os brancos sabem dançar, no qual concorrem três diferentes olhares, que fazem, cada qual, as partes que compõem o 
livro: um músico angolano detido pela polícia na fronteira da Suécia com a Noruega, a caminho de um festival em Oslo, com o passaporte vencido (o "próprio" Kalaf); uma professora de Kizomba, filha de uma retornada, cujos encontros fazem unir musicalmente Brasil, Portugal e Angola; e, por último, um policial norueguês, responsável pela detenção de Kalaf - e que, curiosamente, é fã do rapper Jay-Z.

Personagens tão diferentes entre si, mas que se conectam por um único interesse: a música negra. Embora represente uma figura de poder, a voz do policial, que toma conta da terceira parte do livro, também esboça angústias, paixões, empatias. Transformado policial por uma comodidade familiar, a personagem traça sua história também contemplando seus interesses musicais que atravessam oceanos. Tal curiosidade desperta sensibilidade diante de temas aparentemente distantes do cotidiano norueguês, como episódios de racismo, inclusive protagonizados pela polícia norueguesa, assim como a relação de seu país com os imigrantes e refugiados, que fazem a personagem relembrar de passagens da história da música negra mundial e de trechos de letras de seu ídolo Jay-Z. Mas também memórias de sua infância atravessam sua narrativa, quase sempre combinando um paralelo inesperado com o Hip Hop.

É justamente este o policial que fica encarregado de descobrir se aquele angolano detido na fronteira está falando a verdade. Enquanto os demais policiais tendem a desconfiar da existência de uma espécie de "techno africano denominado kuduro", nossa personagem da parte III é motivada pela curiosidade em torno do gênero:

“Não achas estranho Angola produzir techno? Sempre pensei que a música africana era feita com instrumentos, guitarras, congas e maracas, o oposto de música feita com computadores." Mari achava que a história não fazia sentido. Não encontramos nada na bagagem que o incriminasse, tirando os documentos caducados, é claro. Mas para ela existia algo que não batia certo, tinha que haver alguma outra razão para um homem sair de Lisboa e cruzar a Europa toda de autocarro.

Enquanto ela traçava teorias para tentar encontrar razão que justificasse a razão do músico, eu colocava-me outras questões: o 
que é kuduro? Como apareceu? Quando? Quem o inventou? Como terá o techno chegado até Angola? (...) Como é que essa música foi parar a África? Qual foi o tema que despertou as mentes dos artistas que fazem kuduro? Estas eram as questões que me apetecia colocar e não perguntar quem emitiu o cartão de residência do sujeito que tinha na minha cela. (EPALANGA, 2018, p. 242-243)

A ocorrência da combinação entre música e dança faz com que o romance de Kalaf Epalanga reavalie as identidades portuguesa e europeia de forma distinta às demais obras inscritas na questão negra. Enquanto conta sua trajetória nos países europeus, suas passagens por Londres, Barcelona, Lisboa etc, Kalaf cartografa a evolução do kuduro na Europa dentro da perspectiva de um músico atento às questões políticas e sociais subjacentes:

Se invertêssemos os papéis, ou o hemisfério, eu teria o título da moda, ainda que equivocado, seria chamado de "expatriado", e não com o pejorativo e gasto "refugiado", ou então "cooperante", para recuperarmos um termo com que identificávamos os estrangeiros que vinham ajudar a reconstruir os países do Terceiro Mundo. Eu também estou aqui na qualidade de cooperante, vim para ajudar a reconstruir e redefinir a identidade cultural europeia. (EPALANGA, 2018, p. 67)

A atmosfera "afropolita", assim, converge com a preocupação em redefinir as linhas e fronteiras que estabelecem a identidade europeia e, consequentemente, a identidade portuguesa. Ao pontuar tais reflexões, Epalanga coloca em prática aquilo que Paul Gilroy desenvolve na teoria em seu célebre $O$ Atlântico Negro, ao considerar que os músicos da diáspora negra representam "um tipo diferente de intelectual", cuja especificidade reside em seu exercício político cultural que escapa das relações tradicionalmente promovidas por intelectualidades hegemônicas, estas que tendem a afastar da "massa da população" a importância dos debates candentes (GILROY, 2018, p. 165). 


\section{Esse Cabelo}

Livro de estreia de Djaimilia Pereira de Almeida, autora nascida em Angola e que cresceu nos arredores de Lisboa, Esse Cabelo se destaca não apenas pela centralidade da experiência racializada a partir do cabelo crespo - comum a tantas mulheres negras - como também pela forma com que é construída: os fortes elementos do gênero ensaístico presentes na narrativa se encontram com um olhar crítico diante do repertório consagrado em torno da identidade negra, conferindo um tom reflexivo que rebate tais categorias estabilizadas, ajustando-se, com isso, a uma vivência negra portuguesa.

Mila começa considerando sua "declarada ignorância quanto à toponímia de Luanda" como estratégia narrativa que a faz escapar "de um cortejo de lugares-comuns da lusofonia" (ALMEIDA, 2015, p. 34), já que teria saído da cidade africana ainda criança para mudar-se definitivamente para Portugal. A narradora volta-se, então, à experiência nos salões de cabeleireiros: "A casa assombrada que é todo cabeleireiro para a rapariga que sou é muitas vezes o que me sobra de África e da história da dignidade dos meus antepassados" (ALMEIDA, 2015, p. 14). O cabelo se torna o marcador temporal e espacial da narrativa, assumindo o lugar da metonímia da experiência racialmente marcada em Portugal e a imagem poética que compõe a transição do tempo/espaço da personagem. Esta passagem no tempo é encenada, principalmente, pela transformação capilar:

Tudo aquilo com que posso contar é com um catálogo de salões, com a sua história de étnicas no Portugal que me calhou (...). A história da entrega da aprendizagem da feminilidade a um espaço público que partilho, talvez, com outras pessoas não é o conto de fadas da mestiçagem, mas é uma história de reparação. (ALMEIDA, 2015, p. 15)

Paralelamente, Mila também se ocupa, nos primeiros capítulos, em traçar sua árvore genealógica. Através das lembranças de seu avô, Castro Pinto, a narradora arremeda uma linhagem familiar a fim de construir a "geopolítica" de 
seu cabelo. Semelhante procedimento ocorre em relação aos salões de cabeleireiros, que traçam, no caminho dos penteados, uma espécie de topografia do continente africano:

Visitar salões tem sido um modo de visitar países e aprender a distinguir feições e maneiras, renovando preconceitos. O Senegal são umas mãos hidratadas, Angola um certo desmazelo, uma graça brutal, o Zaire um desastre, Portugal uma queimadura de secador, um arranhão de escova. (ALMEIDA, 2015, p. 119)

Tais rastros de memória, porém, assim como o mapeamento acima, não constroem, ao longo da obra, um chão identitário estável para o "eu" do texto, uma verdade, a origem de Mila e, por extensão, do cabelo crespo. Nasce, daí, a aporia em torno da própria identidade, o estranhamento perante a própria origem, que perfaz toda a narrativa de Esse Cabelo:

'“Onde deixei a Mila?' O tempo da procura coincide com o tempo da descoberta, exactamente como se percebesse o propósito do que escrevo no decurso de escrever. A pessoa que encontrei por acaso confunde-se com o resultado de uma procura apenas no sentido em que, se usarmos uma pá para desenterrar um baú, é possível que o baú encontrado esteja marcado pela pá que usámos. Tal conclusão mostra-me que apenas por acaso este é o meu cabelo. O que somos por escrito é tão diferente do que somos quanto uma nódoa de água é diferente de uma chave" (ALMEIDA, 2015, p. 138)

A suspeição de Mila diante de sua própria origem - a partir da consideração de que esta condiciona a sua identidade - faz com que a narradora, em vez de assumir a tradição histórica do "tornar-se negra/o", se confronte com os espaços já estabelecidos neste discurso. A própria ideia de "retorno à África", intento realizado por Mila ao construir sua árvore genealógica e ao mapear os salões, torna-se, na dinâmica de um self que se estabelece racializado, um recurso paródico a este topos. Manifestado em literaturas engajadas com a negritude, o "retorno à África" e, consequentemente, a enunciação coletivizante, fora expediente temático caro a tais produções. Em Esse Cabelo, especialmente em seus movimentos finais, dá-se sinais de esgotamento de tais gestos, ou seja, nem a postura coletiva e sequer o regresso metafórico à África contribuem para que 
Mila apele para este "eu" próprio das "escritas de si". A imersão na aporia da identidade define, de certa forma, aquilo que Eduardo Lourenço nomeia de "pulsão ensaística", isto é, aquela que "nasce da experiência de cada um como expressão da sua 'instabilidade' ontológica" (BARRENTO, 2010, p. 80-81).

\section{Literatura negra em Portugal?}

Ao analisar o surgimento da negritude no mundo lusófono, Pires Laranjeira destaca alguns dos movimentos que o antecederam e que contribuíram para a formação de uma consciência racial, como Renascimento Negro norte-americano, o Indigenismo haitiano, o Negrismo cubano e o Negrismo brasileiro. Para Laranjeira, a Négritude francesa "usufrui da maturação dos Negrismos caldeados nas Caraíbas, América do Norte e América do Sul" (LARANJEIRA, 1995, p. 47). Por sua vez, a negritude, sendo um discurso que fora difundido nos territórios africanos que lutavam pela sua libertação, tornara-se fundamental para a constituição das literaturas nacionais. A tendência à coletividade se seguiu também em outras produções inscritas na identidade negra, como ocorreu no Brasil com o lançamento da série Cadernos Negros, na década de 1970, em pleno regime militar. Nascida na mesma época em que surgia o Movimento Negro Unificado (MNU), Cadernos Negros participava do processo de dinamização das pautas atreladas à questão racial, contemplando a representação e representatividade artística de negros e negras (CUTI, 2010).

Kenneth W. Warren, em artigo intitulado "Does African-American Literature Exist?" (2011), aponta que o "empreendimento coletivo" que ficou conhecido como literatura afro-americana ou literatura negra não pode mais ser aplicado às atuais produções literárias, pois fora realizada num período histórico específico: a era da segregação racial, na qual vigorava as leis de Jim Crow. Warren continua, afirmando que "uma literatura que insiste que o problema do século XXI ainda é o problema racial obscurece, paradoxalmente, os problemas econômicos e políticos enfrentados por muitos negros americanos, a menos que esses problemas possam ser atribuídos à discriminação racial" (WARREN, 2011, s/n, tradução nossa). 
No caso das obras portuguesas escritas por autores negros, seria possível designá-las como literatura negra? Por estar historicamente atrelado às mobilizações com projetos político-estéticos coletivos, talvez o conceito não se aplique às obras aqui citadas. Contudo, Portugal tem sido, recentemente, palco de inúmeras denúncias de racismo institucional, como os que ficaram conhecidos por "caso Cova da Moura" e "caso Jamaica", além da consequente emergência das demandas da população negro-portuguesa no que diz respeito à discriminação racial. Por isso, o conceito pode aqui ser reivindicado graças a uma ressignificação política, colocando em pauta a importância da questão apresentada também na literatura - não a partir dos referenciais históricos de outrora, mas de um cenário político, econômico e social específicos da atualidade.

Válido lembrar também que a ideia de literatura negra não pode abreviar as possibilidades de experimentação literária dos autores negros. A autonomia, seja ela formal ou temática, também é expediente que deve fazer parte do cotidiano de artistas negros.

\section{Consideraçōes finais}

Embora as obras aqui citadas partilhem de uma ideia de miscigenação da população portuguesa, as três obras, ao apresentarem protagonistas negros, que pensam a partir de uma experiência racializada, que denunciam o racismo, distanciam-se do ideário freyreano lusotropicalista, que instrumentalizou a mestiçagem, transformando-a em ideologia. Por esse motivo, apresentam um ponto de inflexão diante das literaturas que historicamente representam negros e negras 


\section{Referências bibliográficas}

ALMEIDA, Djaimilia Pereira de. Esse Cabelo. Alfragide: Editora Teorema, 2015.

BARRENTO, Joāo. O género intranquilo: anatomia do ensaio e do fragmento. Lisboa: Assírio \& Alvim, 2010.

BUALA. "Entrega das Assinaturas: Campanha por outra Lei da Nacionalidade". 13 de Outubro de $2017 . \quad$ Disponível em $<$ http://www.buala.org/pt/da-fala/entrega-das-assinaturas-campanha-por-outra-leida-nacionalidade> Acesso em: 15 mar. 2019.

CASTELO, Cláudia. Prefácio à presente edição. In: FREYRE, Gilberto. Um Brasileiro em Terras Portuguesas. São Paulo: É Realizações, 2010.

CÉSAIRE, Aimé. Diário de um Retorno a um País Natal. São Paulo: Edusp, 2012.

CUTI [Luiz Silva]. Literatura negro-brasileira. São Paulo: Selo Negro, 2010.

DEPESTRE, René. Bom dia e adeus à negritude. Disponível em: <http://www.ufrgs.br/cdrom/depestre/depestre.pdf> Acesso em: 15 mar. 2019.

EPALANGA, Kalaf. Também os brancos sabem dançar. São Paulo: Todavia, 2018.

FREIRE, Maria da Graça. Portugueses e Negritude. Lisboa: Agência-Geral do Ultramar, 1971.

FREYRE, Gilberto. Um Brasileiro em Terras Portuguesas. São Paulo: É Realizações, 2010. O mundo que o Português criou. São Paulo: É Realizações, 2010b.

GILROY, Paul. O Atlântico Negro: Modernidade e dupla consciência. Rio de Janeiro: Editora 34, 2ª edição, 2012.

HALL, Stuart. A questão da identidade cultural. 2. ed. Campinas: Textos Didáticos, 1998. 
HENRIQUES, Joana Gorjāo. "Falar de etnias ainda é tabu". Público: 22 de Novembro de 2012. Disponível em: <https://www.publico.pt/2012/11/22/sociedade/noticia/falarde-etnias-ainda-e-tabu-1572743> Acesso em: 15 mar. 2019.

. Racismo em português: o lado esquecido do colonialismo. Rio de Janeiro: Tinta-da-China, 2017.

- "Telma Tvon trouxe a juventude negra dos subúrbios de Lisboa para o romance". Público: 15 de Junho de 2018. Disponível em: $<$ https://www.publico.pt/2018/06/15/culturaipsilon/noticia/telma-tvon-trouxe-a-juv entude-negra-dos-suburbios-de-lisboa-para-o-romance-1833901\#gs.NPXNUPKM> Acesso em: 15 mar. 2019.

LARANJEIRA, Pires. A negritude africana de língua portuguesa. Porto: Edições Afrontamento, 1995.

MATA, Inocência. Estranhos em permanência: a negociação da identidade portuguesa na pós-colonialidade. In: SANCHES, Manuela Ribeiro. (Org.). "Portugal não é um país pequeno": contra o 'império' na pós-colonialidade. Lisboa: Cotovia, 2006.

PADILLA, Beatriz; ORTIZ, Alejandra. Fluxos migratórios em Portugal: do boom migratório à desaceleração no contexto de crise. Revista Internacional de Mobilidade Humuna, Brasília, 2012, ano 20, n. 39, p. 159-184.

SENGHOR, Léopold Sédar. Lusitanidade e Negritude. Rio de Janeiro: Nova Fronteira, s.d

SELASI, Taiye. "Bye-bye Babar". The Lip: 3 de março de 2005 < http://thelip.robertsharp.co.uk/?p=76> Acesso em: 15 mar. 2019

SOUZA, Neusa Santos. Tornar-se negro: as vicissitudes da identidade do negro brasileiro em ascensão social. 2.ed. Rio de Janeiro: Editora Graal, 1990.

TINHORĀ0, José Ramos. Os negros em Portugal: uma presença silenciosa. Lisboa: Caminho, 1997.

TVON. Um preto muito português. Lisboa: Chiado Editora 2017. 
WARREN, Kenneth W. "Does African-American Literature Exist?". The Chronicle of High Education: 24 de fevereiro de 2011 < https://www.chronicle.com/article/Does-African-American/126483> Acessao em: 15 mar. 2019.

Recebido em 22/03/2019

Aceito em 29/07/2019 